\title{
Non-Stable Single Event Latch-up
}

\author{
A.I. Chumakov, D.V. Bobrovsky, A.A. Pechenkin, D.V. Savchenkov, G.S. Sorokoumov \\ National Research Nuclear University "MEPhI” \\ Specialized Electronic Systems, aichum@spels.ru
}

\begin{abstract}
Non-stable single event latch-ups (SELs) were analyzed in this paper which vanished without power cycling. This effect depends on the operating conditions of the device under test. The instability of SEL is due to the power drops below the holding voltage. The paper presents experimental results proofing this mechanism of the nonstable SEL occurrence.
\end{abstract}

Keywords - heavy ion, single event latch-up, non-stable SEL, VLSI.

\section{INTRODUCTION}

Single event radiation effects arising in products of micro- and nanoelectronics under the influence of heavy charged particles (HRCs), largely determine the functioning of electronic equipment [1]-[3].The most critical single event effect is the single event latch-up (SEL) in bulk CMOS or BiCMOS VLSI, which sometimes can cause catastrophic failures. Therefore, it is necessary to estimate the SEL sensitivity of bulk CMOS or BiCMOS VLSI intended for use in the electronic equipment of space crafts.

The generally accepted practice to estimate SEL sensitivity of VLSI is based on monitoring the average current flowing through the power supply using current meters built into power supplies that can track the dynamics in the range of units and tens of milliseconds [4], [5].Once a SEL has been detected, it is parried by power cycling the device under test. With this method of SEL registering, it is rather difficult to track non-stable SELs, the duration of which can be units of microseconds. The possible reason for the occurrence of such non-stable SELs may be associated with the effects of power drop, i.e. to the voltage drop on the internal elements of the VLSI and the external elements of equipment [6] - [10].It should be noted that the power drop value strongly depends on the characteristics of the parasitic n-p-n-p structure and on the conditions of the experiment, in particular, the supply voltage, the environment temperature, the VLSI mode of operation and many others.

The paper presents the results of experimental study of non-stable SEL (SENL).

\section{SIMPLIFIED POWER SUPPLY MODEL}

The SEL circuit simulation is carried out, as a rule, using a relatively simple two-transistor equivalent circuit (Fig. 1) [2],[3],[6]. Compared to the classical circuit, a resistor $\mathrm{R}_{\mathrm{IC}}$ is added to this circuit. $\mathrm{R}_{\mathrm{IC}}$ reflects the effect of ohmic voltage drop, both during the flow of ionization current $\mathrm{I}_{\mathrm{IN}}$ inside the circuit, and on the elements of the external equipment. In addition, the capacity of the entire VLSI circuit ( $\mathrm{C}_{\mathrm{IC}}$ ), which can affect the dynamic characteristics of switching on/off the parasitic latch-up structure, is introduced into the equivalent circuit. The value of this capacity is quite large and for modern VLSI it can be $(1 \ldots 10) \mathrm{nF}$.

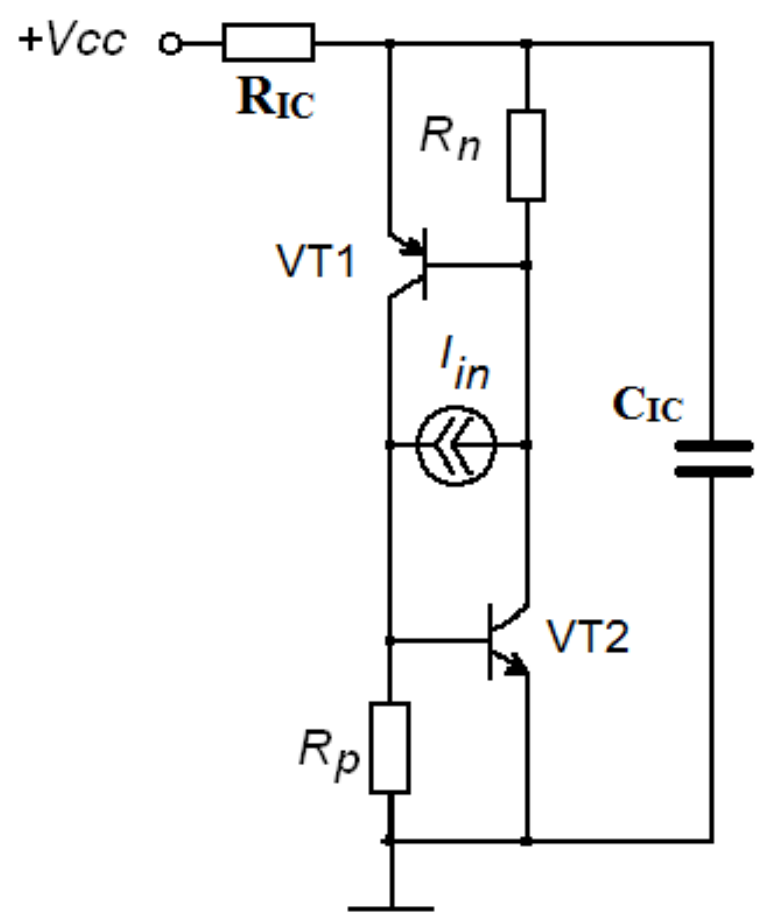

Fig. 1. Simplified equivalent circuitry for the SEL simulation

In most cases, the elements of $\mathrm{R}_{\mathrm{IC}}$ and $\mathrm{C}_{\mathrm{IC}}$ are unknown. Thus the possibility of the emergence of nonstable SEL cannot be estimated right away. In the classic version, the current-voltage characteristic of the latch-up effect is described by an S-shaped curve (Fig. 2). Before the occurrence of latch-up the circuit was in state 1 . When the latch-up arises due to the inclusion of parasitic feedback it goes to state 3 . Only a brief power down below the hold voltage (state 4) allows the circuit to be switched back to state 1 . 


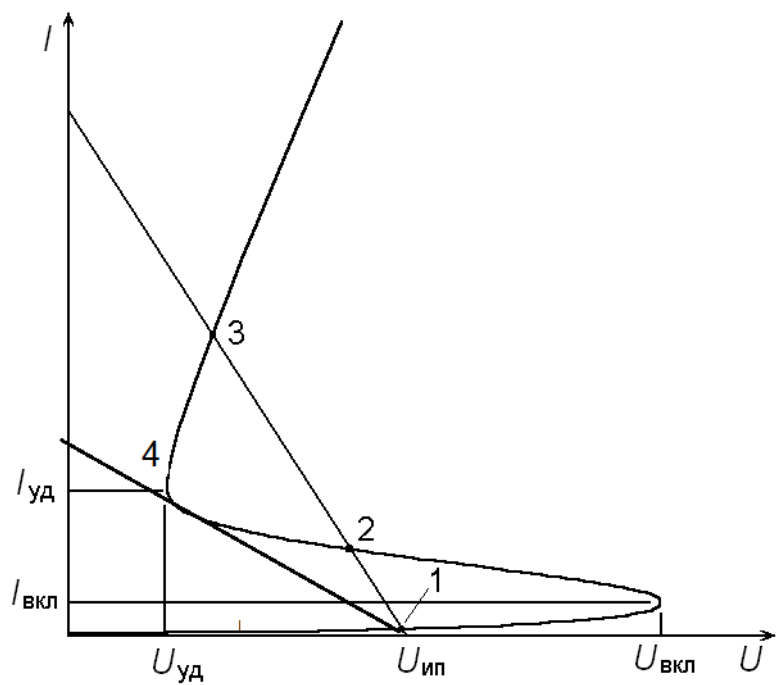

Fig. 2. Current-voltage characteristic of the latch-up effect

Introduction of the resistor $\mathrm{R}_{\mathrm{IC}}$ in the equivalent circuit allows us to take into account thoroughly the effect of power drop. Obviously, in real VLSI this resistance is distributed over the entire area of the chip and differently affects different parasitic n-p-n structures. However, in many cases it allows for taking into account the effect of power drop on SEL sensitivity.

Usually there is a high peak of the supply current during the first tens of nanoseconds after the SEL occurrence (Fig. 3). This sharp increase of supply current is caused by the discharge of the capacitances of the IC and its surrounding circuitry. High current causes high voltage drop across the resistor $\mathrm{R}_{\mathrm{IC}}$. Under certain conditions this can lower the voltage on the IC below the latch-up holding voltage (Fig. 2, state 4). In this case the latch-up will break off with atypical waveform shown in Fig. 4.

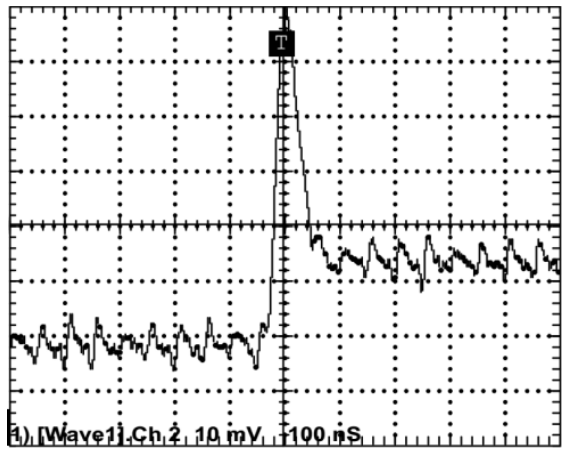

Fig. 3. Typical oscillogram of the current power in the event of a stable latch-up effect

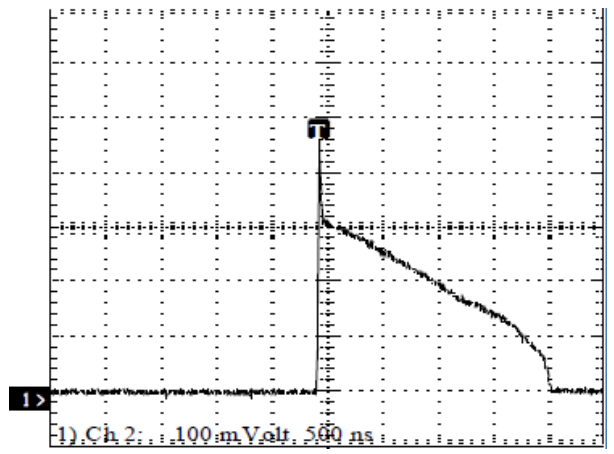

Fig. 4. Typical oscillogram of the current power in the event of a non-stable latch-up effect

\section{EXPERIMENTAL RESULTS}

Experimental SENL studies were carried out for two types of CMOSVLSI: RAM and FPGA. For experiments we used an ion accelerator facility and a focused laser facility with picosecond laser pulse duration.

For RAM, the supply voltage was used as a variable parameter, the change in which allowed us to move the load curve around near state 4 (Fig. 2). For FPGA we studied the influence of its operation mode (static and dynamic) on the estimated SEL sensitivity. In this case, an estimation was made of how much the IC's current consumption in static and dynamic modes would affect the threshold of SEL.

The most interesting results were obtained for the FPGA. It turned out that the IC sensitivity to SEL in dynamic mode with the loaded firmware is much lower than it is in the static mode without loaded firmware.

More detailed studies of the FPGA with the laser facility revealed that in the static mode there are many different latch-up structures with different currents in the steady state (Fig. 5). Experiments with the FPGA in dynamic mode with loaded firmware showed that some SEL structures were not switched-on. Additional investigations showed that there were latch-up structures with a holding voltage of about $2.4 \mathrm{~V}$. This holding voltage is very close to the supply voltage of the IC. Figures 6 and 7 show the current-voltage characteristics of stable and non-stable latch-up structures.

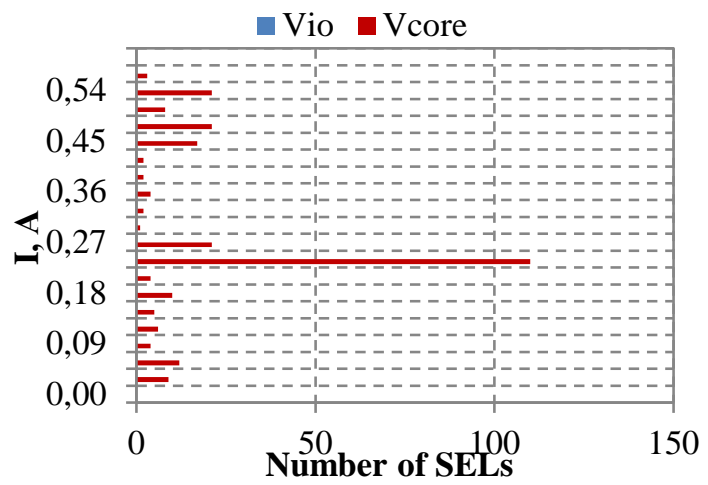

Fig. 5. The dispensation of the latch-up currents in the FPGA in static mode 
In static mode, holding voltage is about $2.4 \mathrm{~V}$ that makes it possible to define the latch-up structure during the irradiation process. This behavior may be due to the high FPGA consumption current (about $60 \mathrm{~mA}$ ) in dynamic mode. This current immediately dislocates the load curve lies below state 4 in fig. 2 . But in static mode, in which the current consumption is about $1 \mathrm{~mA}$, this current is not enough to break the latch-up.

There are also stable SELs in FPGA with holding voltages about $1.2 \mathrm{~V}$, which take place in both static and dynamic modes. The current-voltage characteristic of one of such SELs is shown in Fig. 7.

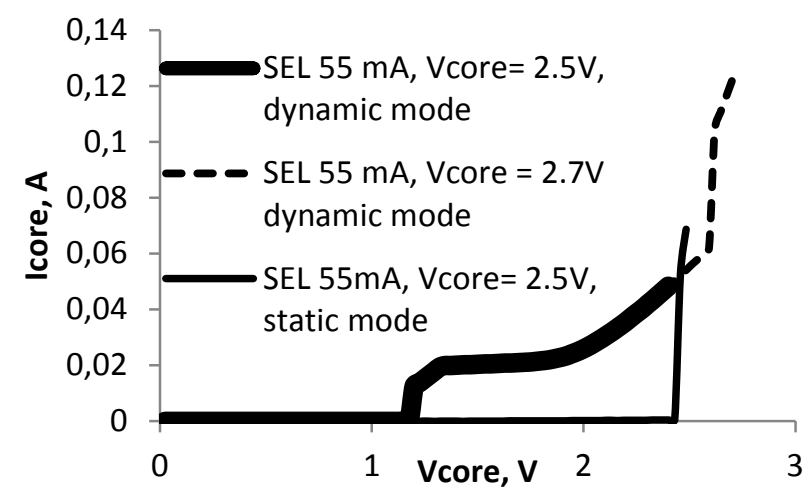

Fig. 6. Current-voltage characteristic of the non-stable SEL in FPGA

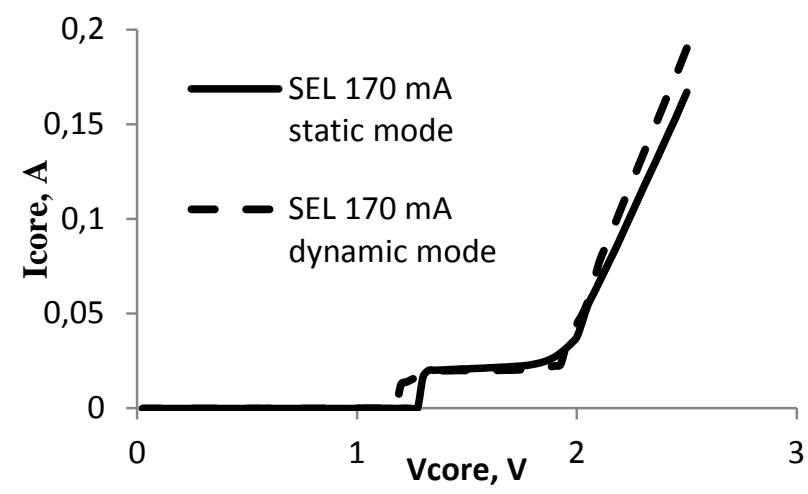

Fig. 7. Current-voltage characteristic of the stable SEL in FPGA

There are both stable and non-stable latch-ups in RAM depending on the supply voltage. In Fig. 8 waveforms for three typical cases are presented as an example. Fig. 8.A shows the waveform of a stable latch-up structure. However, with decreasing supply voltage, it is possible to observe the periodic occurrence and breakdown of SEL (Fig. 8.B), and then the non-stable SEL (Fig. 8.C).

In the framework of the simplified equivalent circuit, all the waveforms presented can be explained. In the first case, the load curve is located above point 4 , so there is no breakdown of the SEL.As the supply voltage decreases due to the initial higher value of the current in SEL, its breakdown occurs. However, it does not have time to completely breakdown, since the latch-up current drops and the parasitic structure is switched on again. And it starts all over again. It was also noticed that the farther the next breakdown is from its initial value, the longer is the duration of being in a state of non-stable SEL. This behavior is due to the internal heating of the VLSI chip, due to which its sensitivity to latch-up increases. Further reduction of the supply voltage leads to a single non-stable latch-up (Fig. 8.C).

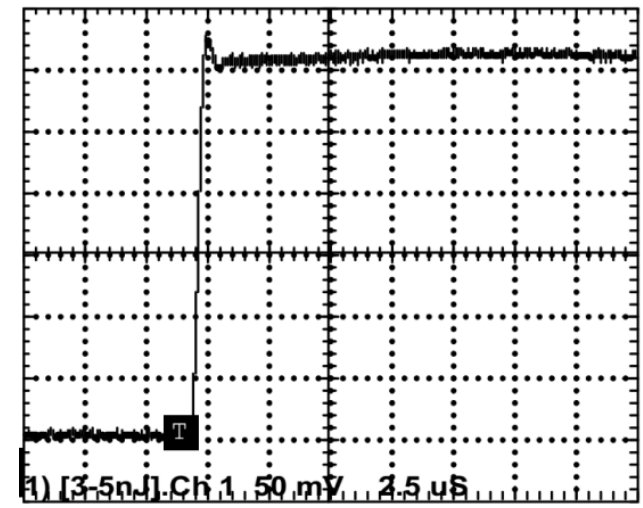

A)

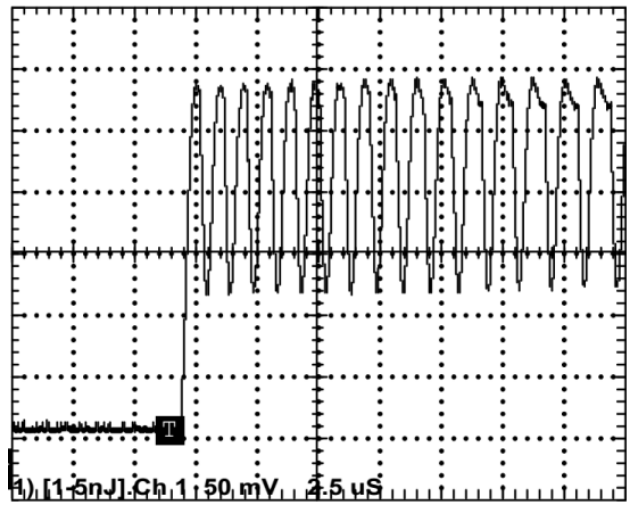

B)

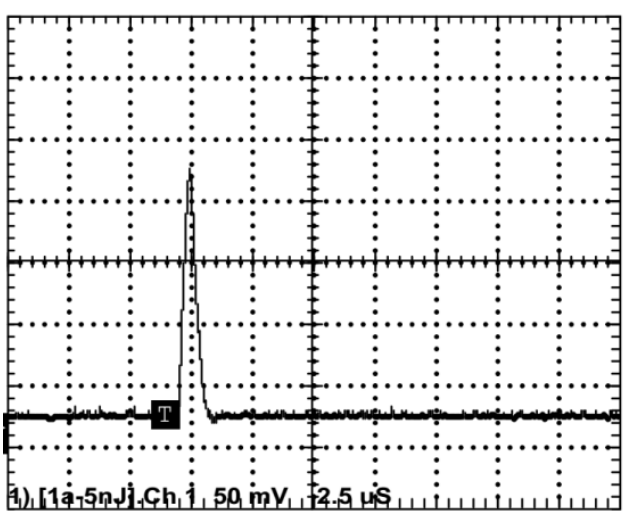

C)

Fig. 8. SELs in the same sensitive area in RAM for different power supply voltages: A) Vcc $=5.5 \mathrm{~V}$; B) $\mathrm{Vcc}=5.0 \mathrm{~V}$; C) $\mathrm{Vcc}=4,9 \mathrm{~V}$.

The presented experimental results indicate that SEL control in the framework of the classical procedure for measuring the average consumption current is not always correct. The presence of non-stable SEL can lead to 
massive failures of VLSI, which by external signs can be classified as a functional failure. In addition, algorithmic methods to improve the system's failure resistance, designed by the hardware developer, such as detecting and correcting one-time and double-time errors in the data word and others, will not work in this situation.

This effect was observed when testing FPGAs and was manifested not in the classic smooth increase in the current consumption due to the accumulation of failures in the configuration memory cells, but in a sharp decrease in the consumption current accompanied by a function control failure.

\section{CONCLUSION}

The presented results of computational-experimental modeling indicate the possibility of the emergence of nonstable SELs in CMOS VLSI under the influence of heavy ions. The cause for these non-stable SELs is associated with the effect of power drop. The importance of the problem increases with the decrease of supply voltage of microcircuits and the increase of current consumption.

Classical methods for SEL registration based on monitoring of the average current in the supply circuit do not guarantee the registration of non-stable SELs in some cases. However, the occurrence of non-stable SELs can lead to massive changes in stored information in registers, triggers and memory cells.

\section{REFERENCES}

[1] Metodologiya obespecheniya stojkosti bortovoj apparatury kosmicheskih apparatov k vozdejstviyu ioniziruyushchego izlucheniya kosmicheskogo prostranstva. Monografiya pod obshch. red. M.V. Yakovleva. M.: MEpHI, 2017380 p(in Russian).

[2] Chumakov A.I. Dejstvie kosmicheskoj radiacii na integralnye skhemy. M.: Radio i svyaz, 2004, 320 p.(in Russian).

[3] Radiacionnaya stojkost izdelij EHKB. Nauchnoe izdanie / Pod red. CHumakova A.I. M.: NIYAU MEpHI 2015, 512 p. (in Russian).

[4] Chumakov A.I., $\quad$ Pechenkin A.A., $\quad$ Egorov A.N., Mavritsky O.B., Baranov S.V, Vasil'ev A.L., Yanenko A.V. Estimating IC susceptibility to single-event latch-up. Russian Microelectronics, 2008, v. 37, \#1 , pp. 41-46.

[5] Pechenkin A.A., Savchenkov D.V., Mavritskii O.B., Chumakov A.I., Bobrovskii D.V. Evaluation of sensitivity parameters for single event latch-up effect in CMOS LSI ICs by pulsed laser backside irradiation tests Russian Microelectronics, v.44 (1), pp. 33-39.

[6] Nikiforov A.YU, Telec V.A., Chumakov A.I. Radiacionnye effekty v CMOS IC. M.; Radio isvyaz, 1994, 180 p., (in Russian).

[7] Massengil T.L., Diehl S.E. Transient Radiation Upset Simulation of CMOS Memory Circuits. IEEE Trans. On Nuclear Science. 1984. V. 31. < 6. P. 1337-1343.

[8] Woodruff R.L., Nelson D.A., Scherr S. Predicting Transient Upset in Gate Arrays. IEEE Trans. on Nuclear Science. 1987. V. 34. < 6. P. 1426-1430.

[9] A. I. ChumakovModeling rail-span collapse in ICs exposed to a single radiation pulseRussian Microelectronics, vol. 35, no. 3, pp. 156-161, 2006.

[10] D. V. Savchenkov, A. I. Chumakov, A.G. Petrov, A. A. Pechenkin, A.N. Egorov, O. B. Mavritskii, A. V. Yanenko, Study of SEL and SEU in SRAM using different laser techniques// Proceedings of 13th European Conference on Radiation and Its Effects on Components and Systems (RADECS). 2013. Oxford. P.1-4. 